\section{A cena interrompida Fin}

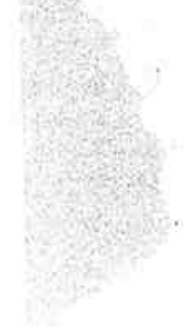

\section{Resumo}

Este artigo corresponde a um capitulo do livro Portaretrato, onde a autora procura resgatar a relaça do leitor com o imaginário e o inconsciente no ato crítico da leitura

Abstract

This article corresponds to a chapter of the book Portaretrato (Picture Frame), in which the author attempts to capture the relationship between the realde, imagination and the unconscious in the critical act.
Universidade de São Paulo

TERESA

Palavras-chave Leitor; imaginário; inconsciente.

Keywords Reader; imagination; unconscious.
Te escrevo como quem se despede da cidade que ama. À margem do Sena, à margem da vida e de nós mesmos, como se pudéssemos sobreviver do pouco que temos. Faço longas caminhadas pelas avenidas suspensas; inquietos magazines se entreolham espantados diante da multidāo anônima que recompōe dia após dia a inércia da paisagem.

Fontaine des Innocents. A modernidade sobrevive à esclerose do sistema. A confluência dos tempos travestidos em punks, beats, beatneaks. Nas paredes arrojadas dos edificios, imagens do velho Halle refletidas em espelho; era curioso o aproveitamento de uma arquitetura secular como forma de reinventar o espaço, uma nova concepçāo do vidro que descristalizava a memória da paisagem fazendo confluir o velho e o novo; como se a modernidade resultasse dessa mobilidade temporal subitamente congelada. Ao contrário do Beaubourg, cuja arquitetura extremamente arrojada nāo alcançava a mesma transitividade temporal aberta para o futuro.

Assim, a cada nova estação podíamos surpreender um ângulo inteiramente novo, o velho Halle escorrendo nos espelhos, como se a memória da paisagem desencadeasse outras memórias, "escorrendo do paletó, da guerra do arco-íris..."

Estou aqui apenas de passagem, o tempo de reconstituir os ambientes, a paisagem. Fui ver o filme do Bergman. "Après la Répétition", j’aime rester sur scène. Os mortos não estão mortos, os vivos nāo passam de fantasmas. Aquela cadeira jả nāo é a mesma, as pessoas se tocam sem nenhuma curiosidade no olhar, um movimento rápido e tudo se reconstitui em gestos apressados. A mesma cena vazia de sempre.

Era a vida que voltava, eu só precisava enquadrar as cenas, escolher o melhor ângulo: o capote de lã cinza, as luvas de pelica marrom que compramos na Irlanda, um frio que enregelava os ossos. Íamos ver uma exposição na Biblioteca Nacional, a poesia de René Char ilustrada pelos pintores contemporâneos. Na sala ao lado, uma exposiçāo fotográfica recompunha a paisagem e os ambientes de "Madame Bovary". A ilusāo já não era ilusāo, o real já nāo era inventado.

Eu tinha chegado a Amsterdā muito cedo pelo trem que passava às $19 \mathrm{~h} 45$ na Gare du Nord, a noite estava escura, mas havia estrelas no céu. Você ia chegar no vôo das $9 \mathrm{~h} 45$, já estávamos no começo da Primavera, as janelas cobertas de flores; eu precisava tomar outro café, era muito cedo, apenas algumas pessoas mal acordadas pelas ruas, o trânsilo leve, o dono do café inquieto com a minha agitação, eu nāo te via desde dezembro, nosso último encontro em minha casa. Em Paris eu ia trabalhar com uma bibliografia mais atualizada sobre a escritura feminina; nos finais de semana acompanhava um seminário dado por Hélène Cixoux no Château de Vincennes, que me atraía muito, nāo só pelo tema (Deuil et Bénédiction), pela novidade do lugar e dos cenários, mas principalmente pelo modo de focalizar a leitura, colocando em destaque a relaçāo do leitor com a obra de Clarice Lispector. 
Uma figura de mulher passa na calçada ao lado, como se ela carregasse a imagem de um luto recente, inusitado. Às vezes é assim que me vejo, como outra disponivel, à disposição de todos os olhares; o chapéu de penas brancas, disfarçada no meio do trânsito. O rapaz da moto pára no sinal vermelho e me olha assustado. As penas brancas eram moda ou sinal vermelho e me
você representava?

Por um momento, a fotografia podia me devolver a mim mesma, mas uma coisa me paralisava. Medo da imagem sinistra desinteriorizada, medo do gesto que acaba. Ajeito o travesseiro, o abajur ao lado. Segura medo do gesto que acaba. Ajeito o travesseiro, o abajur ao lado. jegur era a claridade atravessando os buracos da parede, os porta-retratos.

Mudamos de lugar ou as lembranças viajam? com a sua sala acontecia o mesmo, como se ela viajasse de um lugar para outro e me acompanhasse pelas ruas, às compras de supermercado; os mesmos cadernos desembrulhados, as asas dependuradas no teto, um bilhete apagado com borracha em meio a outros envelopes dispersos. Nenhuma cadeira. Os acolchoados ainda meio a outros envelopes dispersos. Nenhuma cadeira. Os a porta do elevador um perfume que subia e descia até o primeiro andar, um resto de chá nas xicaras e petit-fours no fundo do prato; depois que derrubaram a parede do galpão ficou essa sensação estranha de que as lembranças viajam, como as pessoas, os cenários, trocam de roupa, de sapatos. Você se lembra em que sacola deixei o vaso de avenca, o par de cadarço do meu tênis?

Provação significa que a vida estava me provando; mas provação podia significar, também, que eu estava provando a vida, eu sentia de novo o gosto das coisas e provar era sentir o gosto; a geléia de jabuticaba já nāo era a mesma, nem era o mesmo o gosto dos que partem, sem mesmo saber para onde.

Mas provar podia se transformar numa sede cada vez mais insaciável, eu provava o gosto da laranja, do mel escorrendo nas bordas do frasco. Provar significava começar tudo de novo, eu até já conciliava com a esquerda homeopática, mas queria as estrelas plantadas na praça; era a vida que voltava, eu espiava pela janela a hora em que ela me tomava pelas māos e me levava.

Como você, eu também tentei lutar contra o esquecimento. Como você, eu desejei ter uma memória de sombras e de pedras.

São Paulo, agosto de 1997

Resolvi te escrever, nossas conversas por telefone iam ficando limitadas, agora eu sentia necessidade de puxar de novo o assunto, encompridar conversa; parece que a pesquisa vai tomando forma e segue um rumo inteiramente novo que eu mesma não suspeitava; isso me preocupa um pouco, você conhece essa tendência para a dispersão, para as viagens sem retorno, às vezes me assalta uma sensaçâo incômoda de que vou perdendo de vista toda matéria elaborada anteriormente; no entan- to, é esse caminhar às cegas que parece garantir um certo mistério, é como andar no escuro e, no entanto você sabe, ali estão as tomadas, o interruptor, as cadeiras, as janelas no mesmo lugar de sempre.

Conforme combinamos de outras vezes, estou enviando a você uma leitura mais detalhada desse sonho enigmático e contraditório que acabou nos envolvendo e mudando completamente o rumo da pesquisa; são aind esboços de leitura que seu olhar paciente e instigante vai completar o quadro, afinal você é o único personagem que entra em cena, você é o leitor que me aponta caminhos, que me desconcerta, como quem não me leva sério, assumindo uma atitude ambivalente de quem tem todas as certezas. Isso me inquieta, não era a primeira vez que você me aparecia em sonho, da última vez estávamos ainda em Paris, quando te passei os primeiros escritos sobre Adélia Prado. Naquela época eu nāo tinha ainda muita clareza sobre os impactos do amor e da poesia nos meus hábitos de leitura, eu só percebia um deslizamento de foco e de interesses, que podia estar vinculado ao motivo da viagem e da separaçâo recentes, mas podia tambén ser provocado pela força da imagem poética, pela forma contundente de tocar a experiência do leitor e ser tocada; por outro lado, nāo é difíci imaginar o poder que têm as viagens de tocar zonas mais profundas do entendimento e da percepção e colocar em movimento outras forças que até então se resguardavam, provocando outras formas de deslocamento, como rajadas de vento forte no interior das casas e dos edificios.

E a poesia de Adélia era, naquele momento, a única forma de ver o que não era dado a ver, de poder estar a sós comigo, ausente de mim e assistir de dentro de mim mesma a fratura do ser, no momento em que ele atua numa outra faixa, numa outra cadeia de significaçâo; e a cidade de Paris completava o quadro num jogo irrefletido de múltiplos espelhos devolvendo uma visão descentrada, fora de lugar, fora de foco.

O espelho da chuva nas calçadas, nas ruas, nas grandes avenidas, nas janelas dos bistrôs, nos cafés, o velho Halle escorrendo nas paredes arrojadas dos edifícios, fazendo confluir o velho e o novo.

Paris, capital do amor e do século XXI. Nas entrelinhas do sonho tento resgatar os últimos momentos; a camisa xadrez, a calça branca de alvíssimos quereres, o casaco azul, mal aquecendo seu corpo ávido de sonhos e prazeres. Eu me guardava para você esses anos todos, à espera do amor que nāo chegou a tempo de me tomar pelas mãos, me refazer em algas, em prêmios. Estávamos um diante do outro, à espera do primeiro gesto, impacientes. Além das estrelas e dos planetas, a nossa fome, fome de ser se refazer um no outro.

Participávamos de um exame vestibular, onde você orienta a leitura de um poema sorteado na prova, uma cena corriqueira, embora na vida real nunca tivéssemos trabalhado juntos em banca de vestibular. O que me chama a atenção no sonho é o caráter desconcertante da prova, que me parece pouco comum para os nossos hábitos de leitura, pois não há propriamente 
o texto do poema a ser analisado, não há alunos, nem sala de aula; na sala vazia, apenas a figura do professor, que é também pintor de quadros. Nāo se tratava de um exame vestibular, evidentemente, mas tudo levava a acreditar que fosse, nāo só pela minha natural inquietaçāo diante da prova, mas também, porque nāo dizer, pelo seu modo direto e incisivo de orienta os alunos, que não deixava margem a nenhum outro tipo de interpretação.

Eu ficava intrigada, o sonho tinha portas falsas e eu me deixava enredar pelo engano do sonho que me fazia descobrir outros enganos, como quem se submete a duras provas; a que poema o sonho reportava e porque vocé dominando a cena toda, assumindo uma atitude ambivalente como quem se diverte comigo, com propostas ambiciosas de leitura que nāo deixavam nenhuma pista, ao contrário, despistavam; por que Watteau? qual a relação entre a pintura e o poema, o calendário e a casa? Sua proposta de leitura desconcertava, tirava as coisas fora do lugar, anos de leitura e interpretaçāo de textos que pareciam já nāo ter nenhuma serventia; de que falavam aquelas figuras estranhas e irreverentes, sem nenhum sentido aparente e, no entanto, carregadas de significação; como explicar aquela combinação esdrúxula, impalpável e concreta?

O sonho era aparentemente ingênuo, mas só aparentemente, no fundo era um desafio a toda prova. Ler o que nāo se sabe, ler o que nāo existe. Esse ler é o mais antigo, um ler anterior a toda linguagem; " $\mathrm{Na}$ origem eram as coisas que eram objeto de leitura, os videntes liam as correspondências entre o homem e o cosmos diretamente nas vísceras e nas estrelas. Mais tarde, foi a palavra que passou a ser objeto de leitura, mas na medida em que essas correspondências se preservaram na linguagem falada e nos simbolos da linguagem escrita, a possibilidade dessa primeira leitura nāo desapareceu por completo e está contida potencialmente na linguagem".

Eu tinha Saturno no meio do céu e essa posição do planeta já dava a medida dos desafios que iria encontrar pela frente e do poder que tem o desconhecido de alterar nossas vidas; mas isso significava entrar num terreno escorregadio e complexo, o que eu podia fazer era tentar reconstituir a imagem do sonho e a partir daí buscar uma possível interpretaçāo. Na verdade eu podia distinguir duas sequeências bem nítidas do sonho, interrompidas pelo despertar. Na primeira seqüência você propōe apenas um esboco de leitura do poema que se traduz por uma estranha figura triangular seguida de um retângulo; nenhuma relaçāo explícita entre as figuras, nenhuma indicaçāo mais precisa sobre o poema, apenas o traçado geométrico das figuras desenhadas numa folha de papel em branco. Na segunda seqüência que se segue ao despertar, você propōe uma segunda hipótese de leitura do poema, que aparentemente não acrescenta nada à anterior, apenas disfarça o caráter enigmático e contraditó-

Sérgio Paulo Rouanet, O Édipo e o anjo, itinerários freudianos em Walter Benjamin, Rio de Janeiro, Ediçōes Tempo Brasileiro Ltda, 1981, p. 116 rio do sonho, que se constrói a partir de uma cena interrompida, como um enigma montado noutro enigma.

- "Para entender o poema, era preciso conhecer um quadro de Watteau"; nesse momento preciso do sonho você focaliza em primeiro plano o quadro de Watteau, que, para meu espanto e perplexidade, nāo é um quadro de Watteau. O quadro é um calendário desatualizado que eu tenho dependurado na parede do meu quarto, um calendário suiço de paisagens urbanas e campestres, marcando a entrada da Primavera, as janelas cobertas de flores. O calendário focalizava a fachada de uma casa que mais parecia um chalé suiço, de onde se destacava uma variedade de flores de muitos tons e sobretons, que desciam pela parede encobrindo quase toda a frente da casa.

O que me chama a atenção no quadro é a exuberância das flores e do colorido contrastando com a rigidez geométrica da arquitetura da casa, que parece reproduzir as mesmas figuras contidas na primeira sequêencia do sonho, isto é, os triângulos e retângulos, que agora aparecem no conjunto da casa sob a forma de telhado, janelas, portas, batentes laterais, como se a imagem reproduzisse um contexto de forças em conflito, cuja função é restabelecer o equilibrio

Assim numa primeira leitura do sonho era possível destacar algumas coisas bem evidentes; que o sonho remetia para uma cena interrompida, uma sala vazia, onde não hâ alunos nem o poema sorteado na prova, apenas a figura do mestre que propōe uma primeira leitura do poema, embora este permaneça oculto como um enigma proposto à decifraçāo; a estrutura manifesta da mensagem podia ser explicada pela combinação de duas sequeencias aparentemente desconexas, no entanto a primeira sequêencia, constituída por duas figuras geométricas parecia estar contida na segunda, como uma coisa dentro da outra: a casa dentro do quadro, dentro do quadro o calendário, as figuras geométricas e as flores, que sāo também casa, paisagem, lugar, tempo e espaço simultâneos, explicitando a estrutura folheada do imaginário e do inconsciente.

No entanto, a dificuldade que se colocava para a leitura e interpretaçāo do sonho estava nesse jogo de disfarces, próprio do trabalho do sonho, onde os contrários sāo compatíveis, onde um engano remete a outro engano, onde cada coisa pode ser outra e assim sucessivamente. Eu me sentia insegura, evidentemente não se tratava de um prova e, no entanto, a leitura e interpretação do sonho se colocavam para mim como dura provaçâo; por outro lado, a imagem reproduzida pelo sonho como sendo um quadro de Watteau não era um quadro de Watteau e, no entanto, trazia à tona elementos de uma pesquisa que eu vinha realizando sobre a poesia de Carlos Drummond de Andrade, "O Tempo e as Flores", só que agora expressa em outra voltagem, deslocando-a para a interioridade do sujeito leitor que no sonho se identificava com a imagem da casa; tudo passava pela imagem da casa, que é o lugar da subjetividade, da vida afetiva e das paixōes, da força criadora do desejo, que renasce a cada Primavera. 
O que se podia perceber, num primeiro momento, é que a mensagem pressupunha um desfoque de leitura, evidentemente, sem nenhuma indicaçāo precisa, o objeto da leitura parecia se deslocar de um lugar para outro, de um tempo para outro tempo, que nāo ficava inteiramente claro; podia estar vinculado ao poema que permanece oculto como um enigma a ser decifrado, podia se referir ao quadro de Watteau, que não é um quadro de Watteau, mas é também casa, paisagem, lugar e remete para outras paisagens, outros horizontes. Tudo passava pela imagem da casa, o que me leva a supor que o objeto da leitura podia se deslocar para a interioridade do sujeito e se identificar com ele, nesse caso o objeto da leitura podia ser o próprio sujeito. De que lugar você fala no sonho ? e por que você? essas perguntas iam criando uma rede infinita de relaçōes, ampliando ao máximo as possibilidades de significação, como se o mundo estivesse animado por uma pulsação imaginária e ao mesmo tempo fugaz, o mesmo quando você atira uma pedra no fundo de um lago e brota na superfície uma rede de ondas e oscilaçōes.

Apesar da instabilidade do foco e da multiplicidade de perspectivas, era possivel imaginar que a cena interrompida remeta para um problema de construçāo, isto é, para a construção da casa que é o lugar da subjetividade, da feminilidade, da vida afetiva e das paixōes, cujos elementos da primeira seqüência (as figuras geométricas) se deslocam para a segunda (a casa, o quadro, o calendário), criando uma nova dimensão do tempo e do espaço, da subjetividade e da consciência; o que parece ocorrer, na verdade, é um deslocamento de lugar ou transferência das figuras geométricas que poderiam estar associadas à razão, a objetividade e a consciência para o interior da casa, que é inseparável do mundo e das coisas, para criar uma nova dimensāo da subjetividade e da consciência, que passa pela vida do corpo, do corpo sensivel como transitividade simultânea e reversivel.

Eu ficava embaraçada, a explicação me parecia excessiva e redundante, e além disso eu podia estar extrapolando a leitura, era tudo muito abstrato, escorregadio e concreto, embora eu pudesse localizar aqui e ali alguns "restos diurnos" que entravam na composiçāo da mensagem. Enfim, era eu que fazia a leitura do sonho ou, ao contrário, o sonho que fazia a leitura de mim? provavelmente sim. Eu me deixava levar pelas galerias do sonho sem nenhuma orientação aparente procurando estaquear aqui e ali cada passagem, cada bifurcaçāo, entrava por uma porta, saia por outra e em cada uma delas a mesma inquietaçāo diante do mistério, a mesma sensação vaga, difusa de nāo chegar a nenhum porto. Coisa nenhuma.

No entanto, todas as questões desencadeadas pela leitura pareciam se voltar para ela mesma, a leitura posta em questāo, trazendo à tona elementos de uma pesquisa mais recente onde procuro resgatar a experiência do leitor no ato crítico da leitura; isso significava capturar nas malhas da leitura esse sujeito desconhecido do "eu", fora do tempo e do calendário, mas ao mesmo tempo presente como expansão das diferentes identificaçōes do "eu"; numa palavra, os múltiplos do "eu". É portanto o campo do imaginário que me interessava aprofundar, o registro do sujeito no momento em que ele se cola à imagem, num movimento de identificaçāo, daî a importância do sonho como porta de entrada para o imaginário e o inconsciente; ampliando o horizonte da pesquisa ficava evidente que uma teoria do ensaio voltada para essas relaçōes do leitor com o sujeito do imaginário, devia passar evidentemente pela construçāo da subjetividade e pelo resgate da experiência (abrindo-se para o que não é nós e reconhecendo o que em nós é o mesmo e é o outro, reversiveis e simultâneos). O ensaio seria, portanto a mise en scène desse imaginário, ou para usar uma expressāo sua, o ensaio seria a figuraçāo do "Outro", agarrado nas malhas do inconsciente. Não é por acaso que o quadro de Watteau esteja tão presente no sonho, como o "Indiferente" de Watteau.

Nosso caminho de pesquisa seguia por vias distintas, mas, no fundo, eu sentia em você a mesma curiosidade em relação a esse sujeito "desconhecido do eu", que em seu livro ficava à espreita, aguardando o momento de entrar em cena; é claro que esse momento levou muito tempo para chegar e quando chegou foi de uma forma estranha e inesperada, nem tivemos tempo de comentar coisa nenhuma, porque não havia coisa nenhuma para comentar, a cena já era outra, outro o cenário e ali estávamos nós dois juntos de novo no silêncio mudo de uma sala de espera, à espera daquela viagem repentina para a qual não havia nenhuma urgência. Finalmente livre de todas as amarras e de todas as convençōes você iniciava a longa viagem na noite, explorando suas regiōes mais obscuras e inacessiveis. "Au fond de l'inconnu pour trouver de nouveau."

Só agora reparo, na capa de seu livro lá estão as mesmas figuras geométricas centradas no coração do sujeito. Seria uma evocaçāo de Paul Klee?

Mas de repente tudo ficava apagado e no escuro, como se eu buscasse uma réplica de mim mesma, por onde pudesse captar o negativo da imagem e sua revelação; mas ali, "ilapso nenhum nāo ocorrera", como diria um personagem de Guimarães Rosa, eu podia reconstituir cada etapa do sonho e essas relações iam ficando cada vez mais concretas; havia, de fato, uma cena interrompida, que parecia se completar na segunda seqūência, daí a idéia de construção, de busca de equilíbrio, da mesma forma que $o$ arquiteto busca o equilíbrio da casa; havia um deslocamento de lugar das figuras geométricas para o interior da casa, resultando numa combinação equilibrada entre o excessivo das flores (sensivel) e a rigidez geométrica das figuras (inteligivel) como uma coisa dentro da outra, podendo ser outra e se repropondo de maneira sempre nova e sempre igual (a casa, o quadro, o calendário, as figuras geométricas e as flores).

A explicaçāo me parecia, no minimo, instigante, pois mobilizava vários niveis de leitura, como se o sonho figurasse o processo de construção da imagem (suporte do desejo, da fantasia, da linguagem poética, do imaginário e do inconsciente) e a sua leitura, como dois espelhos 
invertidos postos um diante do outro, como se um figurasse o "Outro", como duas coisas reversíveis e simultâneas.

Apesar dessas relaçōes mais evidentes havia, no entanto, pontos obscuros que valia a pena destacar; uma única voz parece ser, à primeira vista, o ponto de partida para a interpretaçāo do sonho, porque contém em si uma contradição fundamental, que vai ser a pedra de toque da mensagem: "Para entender o poema era preciso conhecer um quadro de Watteau"; é também essa ambivalência intrínseca gerada pela contraposiçāo de duas mensagens, uma que afirma (mensagem verbal) e outra que nega (mensagem visual), que vai desencadear uma série de ressonâncias que remetem para um lado e para outro, para um tempo e outro tempo, estabelecendo correspondências temporais que vão além do tempo e do espaço como se duas melodias caminhassem juntas, em defasagem.

A que poema a mensagem se refere e por que Watteau? Esse o grande desafio, porque se por um lado a mensagem não confere com o quadro (nāo se trata evidentemente de um quadro de Watteau), no entanto a relaçāo entre a poesia e a pintura é imediata, criando uma rede de ressonâncias que remetem para outro tempo, outro espaço, outros textos, outros poemas, onde a relaçăo de correspondência se explicita. O que permanece é a voz de onde emana toda força criadora da mensagem, uma voz que vem do nada e parece caminhar para o nada, uma voz que faz ressoar o passado e o futuro do ser, criando uma terceira dimensāo que engloba e rege todos os tempos.

$\mathrm{Na}$ verdade esse parece ser o princípio que rege a construção da imagem, basta lembrar que a estrutura manifesta da mensagem se caracteriza por duas sequeências bem nítidas, interrompidas pelo despertar e o que permanece é o buraco do sonho, o vazio, o oco, de onde emana a voz e para onde convergem o olhar e a escuta. Nos dois casos, o que se observa é o mesmo princípio, o deslocamento do sentido, o transporte de significação, uma coisa podendo ser outra, tocar a outra como dois espelhos postos um diante do outro como se um figurasse o outro, reversîveis e simultâneos.

O enigma estava montado, o contexto saturnino da representaçāo alegórica me parecia agora mais evidente; o calendário representava o tempo e a História, a seqũência dos dias e dos meses, evidenciando o reinado de Saturno e Cronos, o criador do tempo, "auctor temporum", que governa a medida do tempo e do espaço. Menos evidente era a relaçāo entre a Geometria e a Melancolia, como nos quadros de Dürer, ${ }^{3}$ onde as figuras

${ }^{2}$ José Miguel Wisnik, $O$ som $e$ a sentido. Uma outra história das músicas, São Paulo, Companhia das Letras, 1989, p. 34

Panofsky Klibanski, Fritz Saxl, Saturne et la mélancolie, Trad, do inglês e outras linguas por Fabienne Durond-Bogaert e Louis Évrand, Paris, Ed. Gallimard, 1989, p. 528 geométricas constituem elementos da Melancolia I; no entanto havia ainda essa possibilidade de leitura, isto é, associar a imagem do tempo (calendário), à imagem da melancolia (figuras geométricas), como nos quadros de Dürer, onde ele opera a fusão da tríade, Saturno, Geometria e Melancolia, todos eles vinculados à noçāo de construçāo, basta lembrar que os "metiers", representados na gravura de Dürer, estāo vinculados aos "artificia Saturni" (carpentarius, lapidica, edificator, edificiorum), todos citados por Abû Ma'sar, como tipicamente saturninos, na medida em que estāo ligados à pedra e à madeira.

Evidentemente não se tratava de um sonho qualquer, num momento qualquer; pelo seu poder de deslocamento e condensação, o sonho capturava na imagem uma mensagem do sujeito que virtualmente se oferece para se converter em palavra. No entanto, a mensagem parecia falar de um sujeito ausente, fora do tempo e do calendário; interpretar o sonho poderia ser uma tentativa de reatar o sujeito a sua história e reconstituir o vasto fluxo das percepçōes, imobilizado no imaginário e no inconsciente.

A referência me parecia explícita, na verdade eu estava construindo uma casa no Vale das Flores, que lembrava muito a paisagem suiça, principalmente pelo clima frio das montanhas, localizada na regiāo da Pedra Selada, nos arredores de Visconde de Mauá; a casa ainda estava nos alicerces, mas podia-se ver pela planta que era uma casa enorme, cheia de portas e janelas envidraçadas, que permitiam trazer a paisagem para dentro da casa, diminuindo assim a distância entre o exterior e o interior, a paisagem e a casa.

Já fazia algum tempo que eu vinha me deslocando de um lugar para outro, tentando equilibrar o trabalho em São Paulo e uma situaça nova que resultou da separação dos filhos, do marido e da casa; primeiro aluguei uma casa bem pequena e aconchegante em Maringá, que ficava na divisa do Estado do Rio e Minas, separados pelo Rio Preto, que cortava toda a região desde Maromba, passando por Maringá, Visconde de Mauá, Campo Alegre e Rio Preto, até desaguar no Paraíba, nas proximidades de Bocaina de Minas; a casa de Maringa era bem pequena, mas tinha tudo ou quase tudo, o quintal, a porteira, o pessegueiro florido e o silêncio do rio descendo pela encosta da montanha; eu gostava de me levantar bem cedo para fazer longas caminhadas e respirar o ar puro e seco da madrugada, depois passava pelo curral e ainda trazia o leite espumante tirado na hora. $\mathrm{Eu}$ me fartava de belezas e horizontes, que era, também, uma forma de lidar com a falta; falta de tudo, dos filhos, do marido, da casa.

Ali permaneci durante alguns anos até que a vila nāo suportou o volume de turistas que invadiram a regiāo poluindo o conforto e o sossego do lugar; com isso fui afundando cada vez mais pra dentro da mata, em busca de um lugar mais tranquiilo, onde ainda se ouvia a passarinhada inquieta nos fios do telhado e o barulho do carro de boi, arrastando-se na estrada. Eu fazia um caminho às avessas da pedra no meio do caminho, 
como se eu me esquivasse dela, contornando o Vale das Cruzes, o Vale do Pavāo, a Cachoeira do Alcantilado, a Cachoeira das Antas, uma regiāo cortada por uma infinidade de rios e cachoeiras que formavam quadros de rara beleza, como os sete patamares do Alcantilado que se desdobravam em sete quedas, sem falar nos pequenos lagos que desciam pela encosta do morro, "compondo uma trilha musical só comparável aos caprichos do arco-íris que brotava do fundo das águas".

No entanto, à medida que me aproximava da Pedra Selada, a paisagem ia mudando de figura e a pedra, antes longinqua e escondida pelo curso das águas, agora se mostrava inteira, na sua beleza intacta, desafiando o olhar do viajante com o inusitado da forma na parte mais alta da montanha. A cada movimento do olhar e da estrada, a pedra ia tomando contornos diferentes, como por exemplo, a sela de um cavalo, daí o nome de Pedra Selada; outras vezes, o que se via era a cabeça de um velho deitado no alto do morro, como se fosse o guardiāo do tempo, reinado de Saturno e Cronos; mas era quase impossivel chegar bem perto daquela figura esquiva, no ponto mais alto da montanha, as pessoas tinham que escalar morros e morros, montanhas escarpadas, até chegar bem próximo de ver e quando isso acontecia, a imagem se desfazia como uma ilusāo.

\section{Rodapé \\ Notas de crítica literária}

Os artigos que se seguem foram escolhidos pelas organizadoras da revista Literatura e Sociedade como amostra da atividade crítica que exerci em caráter regular de 1943 a 1947, primeiro no jornal Folha da Manhã, depois no Diário de S. Paulo. Salvo um deles, "Verlaine", todos apareceram em rodapés semanais, com a rubrica invariável "Notas de crítica literária", posta acima do título de cada um. Exceptuado "Sagarana", nunca haviam sido republicados, e eu próprio nāo os tinha mais lido. Aparecem aqui como estavam, salvo correção de gralhas que pude perceber e uma ou outra retificação, além de notas explicativas.

ANTONIO CANDIDO 